\title{
THE DIGITAL TRANSFORMATION OF ASSESSMENT: CHALLENGES AND OPPORTUNITIES
}

\author{
Anžela Jurāne-Brēmane \\ Vidzeme University of Applied Sciences, Latvia
}

\begin{abstract}
In the education sector, the digitization of the learning process has been a topical issue for several decades. It includes various components of the learning process, including assessment, which is an integral part of the learning. Innovative educators have been using technology in assessment for several years, but since March 2020, all educators have been forced to use it. Some educators started using technology without sufficient skills and adequate training, so the forced transformation was not always successful. In most cases, educators learn by doing, as well as developing skills and finding the best technologies for assessment. The aim of this research is to identify opportunities and challenges in the application of technologies in assessment. To achieve this goal, the results of a survey of educators ( $n=181)$ and interviews, both individual and group (26 respondents), were evaluated. The main results are related to the findings of new ideas in assessment, and an exploration of the possibility of providing more frequent and timely feedback. At the same time, there is the challenge of developing needed technological skills, as well as coping with an increase in the amount of work and time required to adequately prepare for the assignments. Having knowledge concerning digital assessment can complement an educator's practice. It gives an insight into a wider study - the post-doctoral research project "Models of Assessment in the Digital Learning Environment (MADLE)".
\end{abstract}

Keywords: feedback, formative assessment, remote teaching and learning, summative assessment, technologies in assessment.

\section{Introduction}

Different types of technologies have been gradually entering the educational process. In short, initially it was the preparation of materials using a computer, then the possibility of posting materials and tests on the Internet that led to online and blended learning developed. From this, applications were created for mobile devices (Farell \& Rushbay, 2016; Milakovich \& Wise, 2019; Kazmi \& Riaz, 2020; Marek \& Wu, 2020). In education, a new learning enhanced by virtual reality technology, which 
makes learning interactive to the highest extent (Roman \& Racek, 2019; Dreimane, 2020). Opportunities to apply different types of technology continue to develop. The digitalization of the educational process, using various technologies for teaching, learning and assessment, has been going on for quite a long time, but so far quite slowly. Technology is not new in education, it has helped to improve existing teaching, learning and assessment methods, as well as being incorporated into administrative support systems (Visvidzi \& Daniela, 2020). Until March 2020, generally, only innovative educators provided technology- enhanced learning. The benefits of such learning have been known for a long time, but it was difficult to encourage educators to use technology, in order to vary instructional methods and tools (Visvidzi \& Daniela, 2019).

Since the spring of 2020, the educational process in most countries has changed significantly because of the forced transition to remote learning. The online opportunities currently being used can provide a dynamic teaching and learning environment, unfortunately, the transformation of the learning process took place without sufficient preparation. At the moment, the priority is for safe, fast and lasting access to teaching materials and support, not the reconstruction of a modern education ecosystem. It is therefore important to distinguish emergency remote teaching and learning from online learning concepts (Mohmmed \& Khidhir, 2020). For educators as well as learners, the acquisition of new technologies has mostly taken place through learning by doing. Nowadays, the importance of ICT skills has significantly increased, and it is important that they be developed by both educators and learners (Williamson \& Eynon, 2020). Researchers also highlight a number of different competencies that are relevant to educators in emergency remote teaching: excellent domain knowledge, proficient computer knowledge, communication skills, clarity of expression, and the ability to emotionally connect with the students (Mishra \& Gupta, 2020). This is, of course, linked to higher workloads and time consumption, however, research also indicates that some educators have experienced a creative flourishing during the pandemic. For example in Finland the assignments for the learners have been versatile, technological solutions have been used in various ways. Educators there have reported positive experiences (Iivari \& Sharma, 2020).

Of course, the provision of emergency remote teaching and learning is associated with various challenges. The transition is quite challenging, as online learning is not always an active process. It is sometimes asynchronous, making it more difficult to implement pedagogical strategies that involve active learner involvement (Kiernan, 2020). Internet access, difficulties in obtaining and using ICT, socio-economic conditions, demotivation and the impact of the home environment are the main factors 
determining the continuity and effectiveness of remote learning (Souza et al., 2020). Research has concluded that there are risks for learners who might not understand the tasks, who might face technical difficulties, as well as situations where student attention might be diverted from learning to other activities (Shim, 2020). Another study lists the main challenges learners face: self-regulation (including procrastination; online help-seeking); technological literacy and competency; students' isolation; technological sufficiency; technological complexity. The main challenges for educators have also been identified: teachers' technological literacy and competency; online video; technological operational; teachers' belief. Two main challenges for educational institutions are identified: technological provision and teacher training challenges. The authors point out that the technological challenges for educators can also be influenced by a reluctance to learn and work with the latest technologies (Rasheed et al., 2020). Studies have also mentioned reduced student-teacher engagement: when learners are less involved in discussions and sometimes do not even answer questions. Mental health is also a challenge, as sudden changes can cause anxiety. Learners who cannot cope with home problems may experience apathy and depression (Oyedotun, 2020). Some researchers point to an increase in the workload of educators, such as the preparation of handouts, videos, differentiation of teaching, and preparing descriptions and explanations. The overall result being that planning one lesson took much longer than a regular training course (Iivari et al., 2020; Mishra et al., 2020). Researchers also point to the risks for students posed by insufficient support from parents or others around them. Younger learners in particular may have difficulty getting up and preparing for work, and difficulty avoiding the temptation to do other activities that interfere with learning (Angelico, 2020; Iivari et al., 2020). Another important, challenging aspect is the issue of academic integrity: educators are not always sure who the author of the work submitted is. In a stressful situation, learners may make poor choices regarding academic ethics. Sometimes cheating in asynchronous, objective and online ratings is unacceptably high. Various options for the restriction of cheating are indicated: question and answer randomization, continuous question development, multiple examination versions, open book options, time stamps, and diversity in question formats, sequences, types, and frequency (Butler-Henderson \& Crawford, 2020; Eaton, 2020). Some of these identified challenges open up new topics for the professional development of educators.

What follows is a brief insight concerning research into the use of technology in assessment and feedback. Information about learning outcomes is identified, collected and interpreted in the assessment process, so it can become an integral part of the teaching and learning experiences. As already 
mentioned, the technology is currently being used in assessment. Research indicates that the application of technologies to assessment can significantly change and enhance learning (Farell \& Rushbay, 2016). In formative assessment, it is important to provide learners with the resources to monitor and adjust their own learning, thus avoiding reliance only on educators' feedback alone. For educators, the key is not just to respond to learning through assessment, but also to direct learning. Feedback from the analysis of formative assessments by educators provides the learner with a new, broader learning experience that can be further included in the learning process (Heritage 2010). Peer-assessment is also being evaluated as an effective didactic strategy for evaluating the answers to open-ended questions related to the development of problem-solving skills. Digital technologies allow a large number of learners to be involved in this process, but they are also useful for supporting small communities of learning (Marsico \& Sciarrone, 2019). The increasing importance of blended and online learning in education, including problem-based and inquiry-based approaches, calls for digital of technologies that can effectively provide formative assessment of informative feedback (Spector \& Ifenthaler, 2016). Educators and learners are able to collaborate through both social and technological resources to control the learning experience and to provide a formative effect from assessment (Daly \& Pachler, 2010). Shute and Kim define e-assessment as the methods and practices that highlight information technologies' role in measuring students' learning (Shute \& Kim, 2011).

Diverse feedback is now available through digital technology. Researchers point out that those involved in the learning process (learners, educators, administrators) must learn to manage the information provided by these various sources and to reduce the tensions arising from inconsistencies. Providing access to a data collection and processing model, not just for final data, is crucial in the development of feedback systems related to an essential aspect of assessment literacy (Webb \& Prasse, 2018). Assessment literacy is described as an adaptive competence with the ability to apply knowledge and skills flexibly in different contexts. Researchers define assessment literacy as an interlinked group of knowledge, skills and positioning that educators can apply to the design and implementation of assessment in different contexts (Pastore \& Andrade, 2019). In order for administrative, curriculum and assessment innovations to be aligned with the requirements of the $21^{\text {st }}$ century, it is essential to support educators in learning and changing assessment practices. Educators with developed assessment competence purposefully link assessment results with appropriate assessment practices (Leong, 2015). The Assessment Competencies Framework was developed several years ago, it includes new and improved assessment practices for the training of educators, as well as clearly defined 
skills educators need to develop their own authentic and adequate assessment practices (Leong, 2015).

Experiences gained during emergency remote teaching can also be applied to the traditional learning process (Iivari \& Sharma, 2020; Angelico, 2020; Oyedotun, 2020). As a result, technologies in the assessment of learners' performance and learning outcomes could be used in the future, making it very important to carefully evaluate the challenges and opportunities of digital assessment. This approach can complement educators' future practice in technology-enhanced assessment.

\section{Method}

Since this paper is only part of a broader study, two methods were used for data collection. First, it included a survey of educators ( $n=181$ ). Second, semi-structured interviews were held, both individual and group, with - 26 individual respondents from seven educational institutions. In both cases, educators from different levels of the Latvian education system participated, as well as from different regions of Latvia. The heads of educational institutions were invited to involve teachers in the study, but participation was entirely voluntary. The collection and processing of data respected all ethical aspects.

As this publication is part of a larger study, only those units that were relevant to the challenges and opportunities were selected. The basic method for data analysis was content analysis (Pipere, 2016), as openended questions were most important in the survey. After coding, the answers were grouped into categories. For interviews, data from transcripts were coded and grouped according to a category matrix using a deductive approach.

Data collection and analysis were limited by different understandings of pedagogical terminology. These differences basically relate to the understanding of the concept of feedback. The second limiting aspect was the focus of educators on the remote learning process as a whole, making it difficult to examine assessment separately.

\section{Results and Discussion}

As mentioned above, in the context of the purpose of this study, the answers to some of the questions of the survey were analyzed, including, changes in assessment, new ideas in assessment and feedback, as well as the difficulties in these processes. From the theoretical framework of the research, three main categories were created: "Feedback and formative assessment" "Summative assessment" and "Technologies". During the 
coding of the data, the subcategories shown in Table 1 and the additional category "Assessment in general" (without subcategories) were created for these initially defined categories. To highlight the most important aspects, the data were quantified by adding up the responses in each subcategory. Table 1 provides examples of some of the most insightful responses.

Table 1. Data from the survey

\begin{tabular}{|c|c|}
\hline $\begin{array}{l}\text { Subcategories } \\
\text { (frequency) }\end{array}$ & Examples \\
\hline \multicolumn{2}{|c|}{ Category "Feedback and formative assessment" } \\
\hline $\begin{array}{l}\text { Investment of time and } \\
\text { amount of workload } \\
\text { (79) }\end{array}$ & $\begin{array}{l}\text { "There was more asynchronous individual feedback } \\
\text { than usual in comment forums, including for written } \\
\text { assignments. Of course, it also took more time than usual." }\end{array}$ \\
\hline $\begin{array}{l}\text { Change of the format } \\
\text { (62) }\end{array}$ & $\begin{array}{l}\text { "The form for the feedback had to be changed to adapt to } \\
\text { the new situation" } \\
\text { "Feedback come through group discussions, individual } \\
\text { conversations, group games, etc." } \\
\text { "I created a lot of self-assessment tests (automated } \\
\text { feedback)" }\end{array}$ \\
\hline \multicolumn{2}{|c|}{ Category "Summative assessment" } \\
\hline Criteria (56) & $\begin{array}{l}\text { "Had to revise the criteria" } \\
\text { "Changed the weight / importance of the criteria in the } \\
\text { overall assessment" } \\
\text { "The criteria need to be reformulated so that students could } \\
\text { understand them" }\end{array}$ \\
\hline $\begin{array}{l}\text { Authorship, plagiarism } \\
\text { (42) }\end{array}$ & $\begin{array}{l}\text { "many thoughts about replacing text writing to avoid } \\
\text { plagiarism" } \\
\text { "In order for students not to be able to submit work done } \\
\text { by someone else in their place, had to think about the } \\
\text { conditions of the task, and the form" }\end{array}$ \\
\hline \multicolumn{2}{|l|}{ Category "Technologies" } \\
\hline $\begin{array}{l}\text { ICT skills development } \\
\text { (68) }\end{array}$ & $\begin{array}{l}\text { "I learned the interactive task environment" } \\
\text { "I use audio recording capabilities" } \\
\text { "I learned about various apps and websites that I didn't } \\
\text { know about or had only heard of before" }\end{array}$ \\
\hline Barriers (29) & $\begin{array}{l}\text { "Some students had difficulty with technology when trying } \\
\text { to complete the assignments" } \\
\text { "Internet access is not always sufficient" } \\
\text { "not everyone has access to new technologies" }\end{array}$ \\
\hline \multicolumn{2}{|c|}{ Category "Assessment in general" } \\
\hline $\begin{array}{l}\text { Assessment in general } \\
\text { (17) }\end{array}$ & $\begin{array}{l}\text { "Learners were late in completing their tasks" } \\
\text { "Each type of assessment had to be specifically adapted and } \\
\text { this posed a really big challenge" } \\
\text { "I created far more tasks for both formative and summative } \\
\text { assessment to motivate students to engage responsibly in } \\
\text { remote learning" }\end{array}$ \\
\hline
\end{tabular}


Some of the responses covered a broad area, thus covering aspects belonging to different categories, so the frequency of responses is not comparable to the number of respondents. The data was then interpreted according to the concepts of 'challenges' and 'opportunities', which are further developed in the discussion below.

In the semi-structured interviews, the concepts of 'challenge' and 'opportunity' were already included in the basic questions; nine categories were created after data processing and coding. In addition, the answers to the other questions as well as the comments were reviewed, as some included statements related to the challenges and opportunities.

Five categories were identified for the concept 'challenges':

1. Investment of time and workload (16 statements), for example, "very much invested work and time" "students sometimes send work in the evenings, it's hard for me to do everything, I need more time" "I have to work harder to prepare the questions myself, not always enough time".

2. Technology (skills and accessibility) (12 statements), for example, "if the child does not understand technology, then I explain patiently, the phone against the screen, here do it, here do that. As long as he understands" "students make videos with poetry readings, put subtitles in another language of their choice" "if the student does not have access to any technology, then think of an alternative".

3. Illegal help (10 statements), for example, "sometimes there is a feeling that the parents have done it there" "you can never be sure who wrote those words".

4. Regular feedback (19 statements), for example, "feedback, whether you progress and understand, otherwise you won't understand anything further" "at the end of each week, they received a comment from me this and that you did, you did well there, but you still have to look at this".

5. Development of appropriate assignments (15 statements), for example, "when taking exams - questions are prepared in such a way that one cannot manage to find anything on the Internet, the more on thinking to comprehension" "all tasks and formulations must be thought through very carefully so that the information can be conveyed to the student in such an understandable way".

Four categories were identified for the concept 'opportunities':

1. Acquisition of new technologies (16 statements), for example, "both teachers and students learned new technologies" "It is important that what we teachers practice what we have learned from technology, so that it does not disappear in our daily work". 
2. Materials on the Internet (13 statements), for example, "I use uzdevumi.lv (assignments.lv) and similar sites much more often, especially if you can change something there" "I have found so many good materials".

3. The opportunity for learners to make mistakes (8 statements), for example, "in self-assessment tests, they immediately see their mistakes, see an explanation, can learn from it" "in simulations, the task can only be completed when it is completely correct".

4. Automated assessment (7 statements), for example, "there was less discussion about assessment and marks when the system scored points in the test" "you can get results and automated feedback faster".

Some claims are applicable to learners: "the biggest challenge for the students was time management, being able to do and submitting on time" "it was very interesting for students, they like technology".

By summarizing and evaluating the respondents' answers from both data sources, the most significant challenges of digital transformation of assessment can be highlighted. More challenging is the establishment of the adequate assignments (Butler-Henderson \& Crawford, 2020; Eaton, 2020). Two aspects are relevant here: making assignment criteria clear to the learner, and having confidence in the authorship of the submission. Certainly, this is very important for summative assessment, when the grading is of more consequence. Consequently, the additional challenge is to eliminate unwanted help "from the sidelines": cheating, copying, or help from relatives and friends. A greater challenge is to formulate questions that show understanding, not just a reproduction of information. In this context, the next challenge is an investment of work and time in preparing assignments (Mohmmed \& Khidhir, 2020; Eaton, 2020; Mishra \& Gupta, 2020) with wording that everyone can understand and with clear criteria, as well as choosing the types of assignment where cheating is not possible. The challenges are also related to the availability of and skill with digital technology. It is very important that a lack of technological skill does not limit the assessment of the topic (Mishra, \& Gupta, 2020). Attention also must be paid to an availability of computers, smartphones or other resources, including the internet. The next challenge is related to regular and multi-directional feedback (Spector \& Ifenthaler, 2016; Webb \& Prasse, 2018) - establishing regular mid-term reviews for formative assessments.

The research data has also highlighted the most important opportunities provided by the digital transformation of assessment. First, in the digital assessment process, educators and learners acquire new and new technological skills (Williamson \& Eynon, 2020). For educators it is not only about learning new technologies, but also about experiencing some professional 
development. Second, with digital assessment, educators and learners are more aware of the importance of feedback and therefore pay more attention to it (Spector \& Ifenthaler, 2016; Mohmmed \& Khidhir, 2020). Using this approach educators look for and find new technological opportunities for feedback, while learners learn to accept and apply feedback information. The next opportunity is due to the rapid transition to emergency remote teaching (Mohmmed \& Khidhir, 2020). Educators acknowledge that this prompted the search for materials available on the Internet with opportunity to customizing and reusing them. For learners, the possibility to making mistakes and trying again, and thus learning from mistakes was highlighted. The automation of assessment processes, especially regarding to automated feedback has been stressed as an important opportunity for technology-enriched learning processes.

Differences in the prevalence of responses at different levels of the education system are not considered significant, but there are some specific findings related to professional and higher education. First, at these levels of the education system, the use of virtual reality technology is increasing (Dreimane, 2020), so it is important to emphasize that the virtual environment accepts only the right solution. Learners must improve their initial assignment or performance until they have a correct result. Next - in cases when competence is being assessed, a complex assignment is created and assessed by two independent educators. Conversations with the learner in an online conference format is an integral component of such assessment. Finally, the results of work-based learning must be assessed in a real-life location - the work environment in most cases is only face-to-face, therefore, technology cannot be involved.

\section{Conclusions}

This research, like the studies published earlier, shows that the technologies and techniques learned in a crisis situation may have entered the learning process permanently. The following summation is provided to create an awareness of the challenges and opportunities in the digital transformation of assessments:

- because learning outcomes can be limited by the socio-economic situations, specifically a lack of computer hardware, software, and the internet; it is still important to find solutions to compensate for this situation;

- educators have more opportunities for creativity: first, creative solutions to problem situations, and second, what is found on the Internet can inspire educators to create their own materials and assignments; 
- when assessment in a digital environment, the assignment instructions must be understandable, with clear assessment criteria that allow a demonstration of deep understanding, as well as preventing the possibility of including non-qualified knowledge.

Solutions to the aforementioned challenges in this research can result in improved assessment practices, as well as an improved learning environment in general. It is important to realize that the digital transformation of assessment does not mean mechanical replacement of current techniques, but rather the development of new techniques based on proven pedagogy, which will provide better educational outcomes.

\section{Acknowledgements}

This research has been supported by a grant from the European Regional Development Fund project "Models of Assessment in the Digital Learning Environment (MADLE)" No. 1.1.1.2/VIAA/3/19/561 within the Activity 1.1.1.2 "Post-doctoral Research Aid".

\section{References}

Angelico, T. (2020). Educational inequality and the pandemic in Australia: Time to shift the educational paradigm. ISEA, 48(1), 46-53.

Butler-Henderson, K. \& Crawford, J. (2020). A systematic review of online examinations: A pedagogical innovation for scalable authentication and integrity. Computers \& Education, 159, 104024. https://doi.org/10.1016/j.compedu.2020.104024

Daly, C., Pachler, N., Mor, Y., \& Mellar, H. (2010). Exploring formative e-assessment: Using case stories and design patterns. Assessment \& Evaluation in Higher Education, 35(5), 619-636.

Dreimane, L. F. (2020). Taxonomy of learning in virtual reality. Doctoral Thesis. University of Latvia.

Eaton, S. E. (2020). Academic integrity during COVID-19: Reflections from the University of Calgary. ISEA, 48(1), 80-85.

Farell, T., \& Rushbay, N. (2016). Assessment and learning technologies: An overview. British Journal of Educational Technology, 47(1), 106-120.

Heritage, M. (2010). Formative assessment and next-generation assessment systems: Are we losing an opportunity? Council of Chief State School Officers.

Iivari, N., Sharma, S., \& Ventä-Olkkonen, L. (2020). Digital transformation of everyday life - How COVID-19 pandemic transformed the basic education of the young generation and why information management research should care? International Journal of Information Management, 55, 1-6. https://doi.org/10.1016/j.ijinfomgt.2020.102183

Kazmi, B. A., \& Riaz, U. (2020). Techmology-enhanced learning activities and student participation. In K. Daniels, C. Elliott, S. Finley, \& C. Chapmen, Learning and teaching in higher education: Perspectives from a Business School (pp. 177-183). Edward Elgar Publishing. 
Kiernan, J. E. (2020). Pedagogical commentary: Teaching through a pandemic. Social Sciences \& Humanities Open, 2, 1-5. https://doi.org/10.1016/j.ssaho.2020.100071

Leong, W. S. (2015). Teachers' assessment literacies and practices: Developing a professional competency and learning framework. Advances in Scholarship of Teaching and Learning, 2(2), 1-20.

Marek, M. W., \& Wu, P. N. (2020). Digital learning curriculum design: Outcomes and affordances. In L. Daniela (Ed.), Pedagogies of digital learning in higher education (pp. 163-182). Routledge. https://doi.org/10.4324/9781003019466-9

Marsico, M., Sciarrone, F., Sterbini, A., \& Temperini, M. (2019). Educational data mining for peer assessment in communities of learners. In A. Visvidzi, M. D. Lytras, \& L. Daniela (Eds.), The future of innovation and technology in education: Policies and practices for teaching and learning excellence (pp. 203-220). Emerald Publishing Limited.

Milakovich, M. E., \& Wise, J. M. (2019). Digital learning: The challenges of borderless education. Edward Elgar Publishing.

Mishra, L., Gupta, T., \& Shree, A. (2020). Online teaching-learning in higher education during lockdown period of COVID-19 pandemic. International Journal of Educational Research Open, 1-24, https://doi.org/10.1016/j.ijedro.2020.100012

Mohmmed, A. O., Khidhir, B. A., Nazeer, A., \& Vijayan, V. J. (2020). Emergency remote teaching during Coronavirus pandemic: The current trend and future directive at Middle East College Oman. Innovative Infrastructure Solutions, 5(72), 71-82. https://doi. org/10.1007/s41062-020-00326-7

Oyedotun, T. D. (2020). Sudden change of pedagogy in education driven by COVID-19: Perspectives and evaluation from a developing country. Research in Globalization, 1-20. https://doi.org/10.1016/j.resglo.2020.100029

Pastore, S., \& Andrade, H. L. (2019). Teacher assessment literacy: A three-dimensional model. Teaching and Teacher Education, 84, 128-138.

Pipere, A. (2016). Datu analīzes metodes kvalitatīvā pētijumā (Data analysis methods in qualitative research). No K. Mārtinsone, A. Pipere, D. Kamerāde (Red.), Pētniecỉba: teorija un prakse. RaKa.

Rasheed, R. A., Kamsin, A., \& Abdullah, N. A. (2020). Challenges in the online component of blended learning: A systematic review. Computers \& Education, 144, 1-17. https://doi.org/10.1016/j.compedu.2019.103701

Roman, T. A., \& Racek, J. (2019). Virtual reality as a pedagogical tool to design for social impact: A design case. TechTrends 63, 79-86. https://doi.org/10.1007/ s11528-018-0360-z

Shim, T. E., \& Lee, S. Y. (2020). College students' experience of emergency remote teaching due to COVID-19. Children and Youth Services Review, 119, 1-7. https://doi. org/10.1016/j.childyouth.2020.105578

Souza, G. H. S., Jardim, W. S., Lopes Junior, G. L., Marques, Y. B., Lima, N. C., \& Ramos, R. S. (2020). Brazilian students' expectations regarding distance learning and remote classes during the COVID-19 pandemic. Educational Sciences: Theory and Practice, 20(4), 65-80. http://dx.doi.org/10.12738/jestp.2020.4.005

Spector, J. M., Ifenthaler, D., Samspon, D., Yang, L., Mukama, E., Warusavitarana, A., Lokuge D. K., Eichhorn, K., Fluck, A., Huang, R., Bridges, S., Lu, J., Ren, Y., Gui, X., Deneen, C. C., San Diego, J., \& Gibson, D. C. (2016). Technology enhanced formative assessment for $21^{\text {st }}$ century learning. Educational Technology \& Society, 19(3), 58-71. 
Visvidzi, A., \& Daniela, L. (2019). Technology-enhanced learning and the pursuit of sustainability. Sustainability, 11(15), 1-7. https://doi.org/10.3390/su11154022

Visvidzi, A., Daniela, L., \& Chen, C. W. (2020). Beyond the ICT- and sustainability hypes: A case for quality education. Computers in Human Behavior, 107, 1-3.

Webb, M. E., Prasse, D., Phillips, M., Kadijevich, D. M., Angeli, C., Strijker, A., Carvalho, A. A., Andresen, B. B., Dobozy, E., \& Laugesen, H. (2018). Challenges for IT-enabled formative assessment of complex $21^{\text {st }}$ century skills. Technology, Knowledge and Learning, 23, 441-456. https://doi.org/10.1007/s10758-018-9379-7

Williamson, B., Eynon, R., \& Potter, J. (2020). Pandemic politics, pedagogies and practices: digital technologies and distance education during the coronavirus emergency. Learning, Media and Technology, 45(2), 107-114, https://doi.org/10.1080/17439884.2 020.1761641 